\section{A esfera pública levada a sério}

Marcelo NEVES. Entre Têmis e Leviatã - uma relação difícil: o Estado democrático de direito a partir e além de Lubmann e Habermas. São Paulo, Martins Fontes, 2006. 354 páginas.

\section{Orlando Villas Bôas Filho}

Um dos problemas fundamentais enfrentados pelo direito na sociedade contemporânea decorre da ausência de um plexo de valores válido como padrão de comportamento em todas as esferas da vida social. A dissolução desse plexo, com a decorrente emergência de uma sociedade pluralista caracterizada por diversas visões de mundo irreconciliáveis, retira a possibilidade de uma fundamentação inquestionável do direito, trazendo, como conseqüência, de um lado, o problema de sua redução à mera facticidade da imposição coercitiva e, de outro, da pretensão de legitimidade que agora não pode mais estar fundada em pressupostos legitimadores dados a priori.

Essa é a questão fundamental que anima a análise realizada por Marcelo Neves em Entre Têmis e Leviatã - uma relação difícil, que, baseado na teoria dos sistemas e na teoria do discurso, aborda as vicissitudes enfrentadas pelo Estado democrático de direito na atualidade, sobretudo no que concerne à articulação entre a facticidade do poder estatal e a pretensão de legitimidade do direito que, em sua análise, são associadas, em termos metafóricos, às figuras de Leviatã e Têmis, respectivamente.

Para dar conta da tarefa a que se propõe, a obra está estruturada em cinco capítulos seguidos de um excurso, intitulado "Perspectiva: do Estado democrático de direito ao direito mundial heterárquico ou à política interna mundial?”, inserido à guisa de observações finais, no qual são discutidos os impactos engendrados pela emergência de ordens jurídicas globais no plano do Estado democrático de direito.

$\mathrm{Na}$ estruturação da obra percebe-se claramente - inclusive por indicação do próprio autor - um nexo entre os capítulos que permite dividi-la em duas partes: a primeira, abrangendo os três primeiros capítulos, apresenta uma pormenorizada análise reconstrutiva dos modelos teóricos com os quais o autor dialoga e a segunda, que abarca os dois últimos capítulos e o excurso que figura como con- clusões finais, veicula o modelo de fundamentação e as condições de realização do Estado democrático de direito, além de abordar criticamente os novos problemas que lhe são impostos pela emergência de ordens jurídicas globais e pela política mundial.

Os três capítulos iniciais reconstroem criticamente os modelos propostos por Luhmann e Habermas, pontuando seus distanciamentos e, o que é mais interessante, seus paralelos. Trata-se de uma análise que, além de desvelar convergências e divergências entre esses dois paradigmas, também procura apontar as limitações apresentadas por ambas. Ainda nessa primeira parte da obra, além da exposição da teoria dos sistemas de Luhmann e da teoria do discurso de Habermas, Marcelo Neves também já começa a apontar as limitações apresentadas por elas para lidar com o pluralismo que caracteriza a sociedade complexa hodierna, aspecto esse que será retomado e aprofundado em seguida.

A segunda parte se inicia pela retomada comparativa dos traços básicos dos modelos de Luhmann e Habermas a respeito da modernidade e do Estado democrático de direito, indicando, sobretudo, a ênfase dada pelo autor da teoria dos sistemas ao dissenso conteudístico que caracteriza a sociedade moderna e a ênfase da teoria do discurso na obtenção do consenso a partir de procedimentos com potencialidade normativa universal.

Feita essa comparação inicial, Marcelo Neves enfatiza a sobrecarga que a pretensão consensualista do modelo habermasiano impõe ao horizonte dos agentes comunicativos ("mundo da vida"), tornando-o, segundo o autor, incapaz de dar conta adequadamente da divergência em torno de conteúdos morais e valorativos que são próprios da sociedade moderna, caracterizada pela superação da moral conteudística e hierárquica que marca as sociedades tradicionais. Embora não desconsidere o fato de que Habermas concebe o consenso como um "ideal regulativo", Marcelo Neves ressalta que o autor alemão se manteria preso a um racionalismo idealista incompatível com a complexidade da sociedade hodierna.

Assim, ao enfatizar a insuficiência do conceito habermasiano de intersubjetividade para a apreensão adequada da complexidade da sociedade contemporânea - uma vez que as relações intersubjetivas orientadas para o entendimento comunicativo engendrariam uma pretensão consensualista incompatível com o caráter plural e multifacetado 
que caracteriza as sociedades pós-tradicionais -, Marcelo Neves procura justamente demonstrar que o dissenso acerca dos conteúdos valorativos e das visões de mundo, característico de tais sociedades, não pode ser desconsiderado.

Baseando-se, em parte, na abordagem de Gunther Teubner, o autor propõe uma releitura do modelo habermasiano à luz da teoria dos sistemas, sugerindo que o conceito de "mundo da vida" seja considerado uma esfera social na qual a comunicação é reproduzida por meio da linguagem natural cotidiana e não a partir da especialização que pauta a linguagem dos sistemas funcionais. ${ }^{1}$ Desse modo, Neves caracteriza a sociedade moderna como pautada não pelo consenso, mas pelo dissenso conteudístico decorrente de uma esfera pública pluralista, na qual os conteúdos valorativos e as visões de mun-do discrepantes se entrechocam. Trata-se da idéia de uma "arena do dissenso" que funciona como um campo complexo de interferência e tensão entre "mundo da vida" (entendido, em termos genéricos, como uma esfera social não estruturada sistêmico-funcionalmente), ${ }^{2}$ subsistemas funcionalmente diferenciados (economia, ciência, educação, arte etc.) e sistema constitucional.

No entanto, segundo o autor, a própria continuidade da esfera pública pluralista somente é garantida pela existência de procedimentos constitucionais que assegurem o fluxo livre e eqüitativo de valores, expectativas e interesses heterogêneos, razão pela qual o consenso procedimental se impõe como pressuposto imprescindível à própria salvaguarda do caráter plural e multifacetado que caracteriza a esfera pública. E é justamente nesse contexto que o Estado democrático de direito é definido pelo autor como uma forma de intermediação entre consenso procedimental e dissenso conteudístico.

Essa proposta, entretanto, não superestima o processo legislativo em detrimento dos demais procedimentos do Estado democrático de direito. Ao contrário, baseando-se na idéia de "hierarquias entrelaçadas" [tangled hierarchies], proposta por Douglas Hofstadter e amplamente utilizada por Niklas Luhmann, enfatiza a circularidade internormativa e interprocedimental como característica essencial do Estado democrático de direito, com a decorrente rejeição da prevalência hierárquica do processo legislativo em relação aos demais procedimentos, afastando assim o problema da imposição unilateral de conteúdos morais e valorativos que poderia criar restrições incompatíveis com a multiplicidade de visões de mundo que caracteriza a esfera pública pluralista da sociedade contemporânea. A idéia de "hierarquias entrelaçadas" possibilita a inserção crítica permanente no âmbito dos sistemas político e jurídico, o que permite que as visões e os argumentos minoritários permaneçam como possibilidades contínuas de mutação da ordem jurídico-política.

Trata-se, portanto, de uma perspectiva preocupada em manter-se adequada ao caráter plural da sociedade pós-tradicional, na qual não é mais possível conceber a soberania do povo (entendida como forma de heterolegitimação do Estado que, na perspectiva sistêmica, deve articular-se com a autolegitimação proporcionada pela autonomia funcionalmente condicionada e territorialmente determinada do sistema político) em termos da manifestação de uma vontade geral homogênea e unitária. Ao contrário, atento ao caráter heterogêneo que é próprio de uma concepção despersonalizada de soberania do povo - algo que expressa uma posição embasada em pressupostos distanciados das premissas da filosofia da consciência -, o autor procura caracterizá-la em termos de uma "inserção contínua dos mais diversos valores, interesses e exigências presentes na esfera pública pluralista nos procedimentos do Estado Democrático de Direito" (p. 165). Trata-se, assim, de um fator de reciclagem permanente do Estado diante de novas situações e possibilidades, constituindo-se também como condição indispensável à sua heterolegitimação num contexto hipercomplexo marcado pela heterogeneidade ética e pelo pluralismo das posições jurídicas.

Entretanto, Marcelo Neves não se contenta apenas em construir um modelo teórico de Estado democrático de direito com a pretensão de aplicação indistinta a todo e qualquer contexto social. $\mathrm{O}$ autor também se preocupa em indicar o caráter heterogêneo que marca a sociedade moderna, definida como sociedade mundial (ou seja, sem barreiras territoriais à comunicação), que condiciona de maneiras diferentes a realização do Estado democrático de direito, razão pela qual distingue, no desenvolvimento da sociedade moderna, uma bifurcação que leva à sua divisão em uma modernidade central e outra periférica. Trata-se de uma distinção, já explorada pelo autor em outros textos, que constitui um esforço significativo para a superação de uma visão homogeneizada e empiricamente limitada da sociedade moderna. 
Indicadas as diferenças entre esses dois contextos (central e periférico), Marcelo Neves aponta os problemas específicos que o Estado democrático de direito encontra em cada um deles. É nesse sentido que, referindo-se aos países da modernidade central, o autor ressalta que o problema fundamental estaria relacionado com a heterorreferência do Estado (que se expressa tanto na dificuldade de responder adequadamente às exigências dos demais sistemas funcionais, como na dificuldade de uma inter-relação adequada entre política e direito), ao passo que, nos países da modernidade periférica, o problema estaria relacionado essencialmente com a auto-referência deficitária dos sistemas político e jurídico. Na modernidade periférica, definida como negativa, a exclusão social e o bloqueio destrutivo à auto-referência do direito conduziriam a uma situação de "corrupção sistêmica" que apresentaria tendência à generalização na experiência jurídica. Segundo o autor, o Brasil figura justamente como um exemplo de uma sociedade na qual se observa tanto a persistência de privilégios e exclusões que obstruem a construção de uma esfera pública pautada pela generalização institucional da cidadania, como a instrumentalização particularista do direito por indivíduos ou grupos sobreintegrados.

Por fim, são analisadas as pressões engendradas pela dinâmica da sociedade mundial e pelos conflitos étnicos e fundamentalistas sobre o Estado democrático de direito que, segundo o autor, enfraquecem sua capacidade funcional e força integrativa, ensejando a necessidade de busca de mecanismos, procedimentos e instituições que forneçam alternativas, com caráter jurídico e político, à incapacidade regulatória e aos déficits funcionais do Estado. Para tanto, empreende uma análise que conjuga tanto a perspectiva de Gunther Teubner como a proposta de Jürgen Habermas.

É preciso notar que, embora esteja baseada em perspectivas teóricas aparentemente irreconciliáveis, a proposta de Marcelo Neves não consiste numa abordagem eclética que busca levar a um denominador comum dois modelos que, como é sabido, divergem em pontos nevrálgicos. Trata-se, antes, de uma apropriação original e conseqüente que retira, de ambos, os elementos necessários à construção de um modelo mais abrangente, cuja pretensão é dar o devido relevo ao dissenso conteudístico que marca a esfera pública pluralista da sociedade moderna.

\section{Notas}

1 Embora se inspire na proposta de Gunther Teubner, Marcelo Neves extrai dela aspectos inexplorados, agregando-lhes maior precisão analítica, o que lhe permite evitar as críticas enfrentadas pelo autor alemão, especialmente a que lhe é endereçada por Jürgen Habermas no livro Direito e democracia: entre facticidade e validade.

2 Marcelo Neves, diferentemente de Habermas, não considera o conceito de "mundo da vida" como o horizonte dos "agentes comunicativos" orientados à busca do entendimento intersubjetivo, pois, segundo ele, isso o sobrecarrega com uma pretensão consensualista (p. 125).

\section{ORLANDO VILLAS BÔAS FILHO}

é bacharel em Direito (PUC/SP), História

(USP) e Filosofia (USP). Mestre e doutor em

Direito pela Faculdade de Direito da USP, é pesquisador do Núcleo de Direito e

Democracia do Centro Brasileiro de Análise

e Planejamento - Cebrap e professor da

Faculdade de Direito da Universidade Presbiteriana Mackenzie.

E-mail: ovbf@mackenzie.br. 